\title{
Yaşı kalça kırıklarında cerrahi zamanlama ne olmalıdır?
}

\author{
What should be the timing for surgery in elderly hip fractures?
}

\author{
Esra Akdaş Tekin¹, Ali Çağrı Tekin²
}

1SBÜ Prof. Dr. Cemil Taşçığlu Şehir Hastanesi, Anestezi ve Reanimasyon Kliniği, İstanbul ${ }^{2}$ SBÜ Prof. Dr. Cemil Taşçıoğlu Şehir Hastanesi, Ortopedi ve Travmatoloji Kliniği, İstanbul

\begin{abstract}
Kalça kırı̆̆ı insidansı yaşlanan nüfusla beraber hızla artmaktadır ve şu anda yüksek mortalite oranı nedeniyle dünyadaki en önemli sağlık sorunlarından biridir. Kalça kırıkları yaşlı popülasyonunda hastaneye başvuru sebeplerinde de ön sıralarda yer alır. Yaşlı popülasyonda kalça kırıklarının en sık nedeni basit düşmelerdir. İleri yaşta gecikmiş cerrahinin ameliyat sonrası sonuçlar üzerindeki etkisi geniş ölçüde tartışılmaktadır. Yaşlılarda kalça kırıkları için farklı tedavi kılavuzları ameliyatın mümkün olan en kısa sürede yapılmasını tavsiye etmektedir. Gecikmiş cerrahi ve ameliyat sonrası mortalite arasındaki ilişki konusunda görüşler farklık göstermektedir. Kılavuzların ötesinde geciktirici cerrahiyi tercih edenler, bu yaklaşımın hastaları tıbbi olarak optimize etmek ve dolayısıyla ameliyat öncesi ve sonrası komplikasyon riskini azaltmak için gerekli olduğuna inanmaktadır. Başvurudan sonraki 48 saat içinde yaşlılarda kalça kırıkları için cerrahi yapılması en iyi uygulama gibi görünmektedir. 48 saat içindeki erken kalça cerrahisi daha düşük mortalite ve daha az ameliyat öncesi ve sonrası komplikasyon ile ilişkilendirilmiştir. Erken tedavinin savunucuları, bu yaklaşımın bir hastanın yatağa bağımlı kaldığı süreyi en aza indirmeyi ve böylece bası yaraları, derin ven trombozu ve idrar yolu enfeksiyonları gibi ilişkili komplikasyon riskini azalttığını iddia etmektedirler.
\end{abstract}

Anahtar sözcükler: kalça kırığı; zamanlama; acil cerrahi
Incidence of hip fracture is rapidly increasing in a population getting older day by day. Moreover, hip fractures are one of the most important healthcare problems around the world due to high mortality rates. Hip fractures are one of the main reasons to hospital admission in elderly. The most frequent etiology for hip fractures in elderly are simple falls. Effect of delayed surgery on postoperative outcomes in seniors are still contradictory. Generally, surgical timing guides recommend early surgery for hip fractures in seniors, although there are alternative opinions on postponed surgery and its effect on surgical outcomes. However; beyond the surgical timing guides, the surgeons who prefer postponed surgery turn to the idea that patients should take medical care before surgery and optimized medical conditions needed for undergoing surgical procedures. Forty-eight hours after admission looks like the most suitable surgical timing on hip fractures in elderly. Early surgery has been related to less mortality risk and fewer perioperative complications. The supporters of early surgery claim that this approach will shorten immobilization; therefore, decrease the risk of deep vein thrombosis, urinary tract infections, skin wound and related complications.

Key words: hip fractures; timing; urgent surgery

\section{Yaş}

Literatürde ameliyat zamanlamasının 24 saatten önce veya sonra olması arasında farklı yaş gruplarında mortalite oranları açısından anlamlı bir fark saptanamamıştır. Yonezawa ve ark., 85 yaş ve üzerindeki hastalarda, 24 saat içinde veya daha sonra ameliyat edilmiş olanlar arasında mortalite açısından istatistiksel olarak anlamlı bir fark olmadığını göstermişlerdir. ${ }^{[3]}$ İncalzi ve ark. da ameliyat zamanı ve yaş arasında herhangi bir etkileşim olmadığını

- Illetişim adresi: Uzm. Dr. Esra Akdaş Tekin, SBÜ Prof. Dr. Cemil Taşçıoğlu Şehir Hastanesi, Anestezi ve Reanimasyon Kliniği, Darülaceze Caddesi No: 27, Okmeydanı, Şişli, İstanbul Tel: 0505 - 6765058 e-posta: dr_esraktas@yahoo.com

- Geliș tarihi: 2 Ocak 2021 Kabul tarihi: 11 Ocak 2021

ORCID iD: Esra Akdaş Tekin, 0000-0001-8538-2893 • Ali Çağrı Tekin, 0000-0002-4308-8167 
bildirmiştir. ${ }^{[4]}$ Ayrıca literatürde 65 yaş üstü kalça kırıklarında ilk 24 saatte cerrahi yapıldığında diğer yaş gruplarından farklı herhangi bir komplikasyon bildirilmemiştir. ${ }^{[5]}$ Güncel literatürde kalça kırı̆̆ı ameliyatında yaşın komplikasyonlarla herhangi bir ilişkisi saptanamamıştır. ${ }^{[5]}$

\section{Cinsiyet}

illeri yaş erkek hastalarda erken cerrahi (24 saat içinde) daha yüksek mortalite ile ilişkili bulunmuş fakat gözlenen bu farklılığın rastlantısal olduğu düşünülmüştür. ${ }^{[6,7]}$

\section{Fiziksel durum}

Literatürde, komorbiditesi olan hastaların 24 saat içinde ameliyat edilmeleri sonrasında mortalitede azalma izlenirken; komorbiditesi (hipertansiyon, diabet, iskemik kalp hastalığı, kalp yetmezliği, pulmoner bozukluklar, kognitif ve nörolojik sorunlar) olmayan hastalarda erken veya geç ameliyat olma arasında mortalite açısından istatistiksel olarak anlamlı bir fark saptanmamıştır. ${ }^{[2,8]}$

Başka bir çalışmada, hastalar fiziksel durumlarına bağlı olarak acil cerrahi için uygun ve uygun olmayan olarak iki gruba ayrılmış, cerrahi için uygun olduğu düşünülen hasta grubunda erken ( 24 saat içinde) ve gecikmiş cerrahi arasında 30 günlük mortalitede istatistiksel olarak anlamlı bir fark gözlenmemiştir. ${ }^{[2]}$ Akut tıbbi komorbiditesi (diyabet, iskemik kalp hastalığı, kalp yetmezliği, pulmoner bozukluklar, nörolojik sorunlar) olan hasta grubunda, cerrahinin zamanlaması ile 30 gün, 90 gün veya bir yıl içindeki mortalite arasında anlamlı bir ilişki izlenmemiştir. ${ }^{[2,8]}$

\section{Cerrahi Zamanlama ve Mortalite}

Kalça kırıklarında cerrahi zamanlama ve mortalite arasındaki ilişki açısından bugüne kadar ortopedi ve travmatoloji uzmanları arasında farklı görüşler bulunmaktadır. ${ }^{[9]}$ Birçok yazar hala erken ameliyatın sağkalımı iyileştirmede önemli bir faktör olduğunu bildirmektedir. ${ }^{[10]}$

ASA (American Society of Anesthesiologists) skorlaması uzun dönemde mortalitenin belirteci olarak kullanılmaktadır. Hamlet ve ark., üç yıllık mortalite oranlarını ASA I ve II olan hastalarda \%23, ASA III ve IV olan hastalarda ise \%39 bulmuşlar, ASA sınıflamasının mortalitenin iyi bir belirteci olduğunu bildirmişlerdir. ${ }^{[1,11,12]}$

Bazı çalışmalar hastaneye başvurudan sonraki 24 saat içinde ameliyat edilen hastalarda ameliyat sonrası 30 günlük mortalite oranının önemli ölçüde daha düşük olduğunu bulmuşlardır. ${ }^{[13]}$ Yayımlanmış 16 çalışmanın erken sistemik bir incelemesi, ameliyat sonrası 30 günlük ve 1 yıllık mortalitenin 48 saatten fazla gecikmiş cerrahi nedeniyle arttığını ortaya koymuştur.
Başvurudan sonraki 24-48 saat içinde cerrahi, tüm nedenlere bağlı mortaliteyi azaltmada önemli bir faktör olarak derecelendirilmiştir. ${ }^{[14,15]}$

Öte yandan, birkaç çalışma, gecikmiş cerrahi ile ameliyat sonrası mortalite arasında çok az korelasyon olduğunu ileri sürmüştür. İngiliz ve İrlanda Ortopedi Dernekleri ile Büyük Britanya ve İrlanda Anestezistler Derneği tarafından yayımlanan yönergelerde " $k a$ bul edilebilir gecikme nedenleri"; $<8 \mathrm{~g} / \mathrm{dl}$ hemoglobin değeri, elektrolit dengesizliği, kontrolsüz diyabet, ventriküler yetmezlik, aritmi, akciğer enfeksiyonu ve düzeltilebilir koagülopatiler olarak belirtilmiştir.[16] Bu kılavuzlar, mümkünse bu komorbiditeleri olan hastalarda stabilizasyondan sonra ameliyat yapmanın daha güvenli olacağını önermektedir. Kalça kırığı olan 850 hastanın ileriye dönük bir analizinde, AlAni ve ark., 24 saat, 36 saat ve 48 saat içinde yapılan ameliyatlar arasında mortalite açısından fark olmadığını bildirmişlerdir. ${ }^{[17]}$ Moran ve ark., ayrıca kalça kırığı olan 2660 hastayı ileriye dönük olarak analiz ettiler ve hastaneye yatırıldıktan sonra dört güne kadar olan cerrahi gecikmenin ameliyat sonrası mortalite üzerinde bir etkisi olmadığını ve hastaneye başvurudan sonraki dördüncü günün mortalite açısından bir eşik olduğunu bildirdiler. ${ }^{[18]}$ Vidán ve ark., kalça kırıklı 2250 hastadan oluşan çalışmalarında, yaş, demans ve kronik hastalık gibi etkenler optimize edildikten sonra hastaneye başvurudan 120 saate kadar olan cerrahi müdahale gecikmesinin ameliyat sonrası mortalite üzerinde etkisinin olmadığı gibi benzer bulgular bildirmişlerdir. Birincil sağlık durumu kötü olan hastaların, ameliyata kadar daha fazla gecikme yaşadıkları ve bu ilişkinin tek başına ameliyatı gecikmiş hastalar için olumsuz sonuçlar ürettiği sonucuna vardılar. ${ }^{[19]}$

\section{Cerrahi Zamanlama ve Hastanede Yatış Süresi}

Birçok çalışma, kalça kırığı olan yaşlı hastalarda erken ameliyatın hastanede kalış süresinin kısalmasıyla ilişkili olduğunu göstermiştir. Lefaivre ve ark., hastaneye yattıktan sonraki 24 saat içinde ameliyat edilen hastalarda ortalama hastanede kalış süresinin dört gün kısaldığını bildirmişlerdir. ${ }^{[9]}$ Cerrahi ile ilgili faktörler (yaş, kırık tipi, tıbbi komplikasyonlar) kontrol edildikten sonra, gecikmiş cerrahi ile hastanede kalış süresinin uzaması arasında bir ilişki olduğu izlenmiştir. Beş günden fazla gecikmiş cerrahi ile hastanede kalış süresinin uzaması arasında anlamlı bir pozitif korelasyon bildirmişlerdir. ${ }^{[9]}$

\section{Cerrahi Zamanlama ve Komplikasyonlar}

Bası yaraları, yaşıılarda kalça kırığı sonrası uzun süreli hareket kısıtlılığından kaynaklanan ciddi morbidite 
oluşturan bir komplikasyondur. Bası yarası insidansı erken cerrahi ile önemli ölçüde azaltılabilir. Literatürde cerrahinin 96 saatten fazla ertelenmesiyle bası yaralarının görülme sıklığının önemli ölçüde arttığı bildirilmiştir. ${ }^{[20]} \mathrm{Bu}$ sonuçlar ile literatürdeki diğer çalışmaların sonuçları arasında benzerlikler görülmekte ve bası yarası insidansı ile cerrahi gecikmesi arasında güçlü korelasyon izlenmektedir. ${ }^{[20,21]}$

Kalça kırığından sonra hareketsizlik uzadığından ortaya çıkabilecek bir diğer ciddi komplikasyon da pnömonidir. Bası yaralarında olduğu gibi, pnömoni, gecikmiş cerrahi ile önemli ölçüde ilişskilidir. ${ }^{[22]}$

Gecikmiş cerrahi ile venöz tromboembolizm oluşumu arasındaki ilişki üzerine yapılan çalışmalar arasında bazı farklılıklar devam etmektedir. ${ }^{[23]}$ Shin ve ark., gecikmiş cerrahi olgularında venöz tromboembolizme bağlı ciddi komplikasyonları önlemek için ameliyat öncesi kapsamlı aktif tahlil ve tetkik önermiştir. ${ }^{[23]}$

Kalça kırığı olan yaşlı hastalarda kısa ameliyat süresinin uzun dönem fonksiyonel sonuçları olumlu etkilediği bildirilmiştir. Olası "kabul edilebilir gecikme nedenleri" daha iyi hale getirildikten sonra, 36 saat içinde yapılan ameliyatın dört ay içinde bağımsız günlük hayata dönme olasılığını artırdığı bildirilmiştir. ${ }^{[21]}$ Başka bir çalışmada kırık öncesi ve ameliyat sonrası birinci, üçüncü, altıncı ve on ikinci aylardaki günlük yaşam skorları değerlendirilmiş, hastaneye yatıştan sonraki 5 gün içinde cerrahi yapılabilirse daha erken ameliyat sonrası günlük aktivitelere dönülebileceği bildirilmiştir. ${ }^{[1,2,21]}$

\section{SONUÇ}

Kalça kırı̆ı insidansı, yaşlı hasta sayısında artışla birlikte hızla artmaktadır. Ancak uygun cerrahi zamanlama ile ameliyat sonrası sonuçlar arasındaki ilişki konusunda hala tartışmalar vardır. Literatüre göre, yaşılırda kalça kırıkları için başvuru sonrası hastanın kabul edilebilir sınırlarda olmayan tıbbi parametreleri kontrol altına alındıktan sonra en erken sürede cerrahiyi düşünmek akıllıca olacaktır. Tıbbi stabilizasyon gerektirmeyen hastalar, hastaneye yatırıldıktan sonraki 24 saat içinde ameliyat edilmelidir. Dengede olmayan ama düzeltilebilir bir tıbbi durum varsa, bu hedef kabulden sonraki 48 saat içinde durumun düzeltilmesi olmalıdır. Bu süre zarfında, çeşitli bölümler (örn., dahiliye, anestezi uzmanları) arasında aktif işbirliğine dayalı etkileşimler gerçekleştirilmeli ve ameliyat, sadece bir test veya düzeltilemeyen-düzeltilemeyecek tıbbi durumlar nedeniyle ertelenmemelidir. Literatürde düzeltilemeyen tıbbi nedenlerle ertelenen hastalar en yüksek ölüm oranına sahiptir ${ }^{[2]}$ ve potansiyel olarak erken ameliyattan en fazla yararlanabilecek olan bu hasta grubudur.

\section{KAYNAKLAR}

1. Öztürk I, Toker S, Ertürer E, Aksoy B, Seçkin F. Analysis of risk factors affecting mortality in elderly patients (aged over 65 years) operated on for hip fractures. Acta Orthop Traumatol Turc 2008;42(1):16-21. Crossref

2. Seong YJ, Shin WC, Moon NH, Suh KT. Timing of Hipfracture Surgery in Elderly Patients: Literature Review and Recommendations. Hip Pelvis 2020;32(1):11-6. Crossref

3. Yonezawa $T$, Yamazaki K, Atsumi T, Obara S. Influence of the timing of surgery on mortality and activity of hip fracture in elderly patients. J Orthop Sci 2009;14(5):566-73. Crossref

4. Incalzi R, Capparella O, Gemma A, Camaioni D, Sanguinetti C, Carbonin PU. Predicting in-hospital mortality after hip fracture in elderly patients. J Trauma 1994;36(1):79-82. Crossref

5. Weller I, Wai EK, Jaglal S, Kreder HJ. The effect of hospital type and surgical delay on mortality after surgery for hip fracture. J Bone Joint Surg Br 2005;87-B(3):361-6. Crossref

6. Hapuarachchi KS, Ahluwalia RS, Bowditch MG. Neck of femur fractures in the over 90s: a select group of patients who require prompt surgical intervention for optimal results. J Orthop Traumatol 2014;15(1):13-9. Crossref

7. Haleem S, Lutchman L, Mayahi R, Grice JE, Parker MJ. Mortality following hip fracture: trends and geographical variations over the last 40 years. Injury 2008;39(10):115763. Crossref

8. Carpintero P, Caeiro JR, Carpintero R, Morales A, Silva S, Mesa M. Complications of hip fractures: a review. World J Orthop 2014;5(4):402-11. Crossref

9. Lefaivre KA, Macadam SA, Davidson DJ, Gandhi R, Chan $\mathrm{H}$, Broekhuyse HM. Length of stay, mortality, morbidity and delay to surgery in hip fractures. J Bone Joint Surg $\mathrm{Br}$ 2009;91$\mathrm{B}(7)$ :922-7. Crossref

10. Pollmann CT, Røtterud JH, Gjertsen JE, Dahl FA, Lenvik $\mathrm{O}$, Årøen A. Fast track hip fracture care and mortality - an observational study of 2230 patients. BMC Musculoskelet Disord 2019;20:248. Crossref

11. Michel JP, Klopfenstein C, Hoffmeyer P, Stern R, Grab B. Hip fracture surgery: is the pre-operative American Society of Anesthesiologists (ASA) score a predictor of functional outcome? Aging Clin Exp Res 2002;14(5):389-94. Crossref

12. Hamlet WP, Lieberman JR, Freedman EL, Dorey FJ, Fletcher $A$, Johnson EE. Influence of health status and the timing of surgery on mortality in hip fracture patients. Am J Orthop (Belle Mead NJ) 1997;26(9):621-7. Crossref

13. Uzoigwe CE, Burnand HG, Cheesman CL, Aghedo DO, Faizi M, Middleton RG. Early and ultra-early surgery in hip fracture patients improves survival. Injury 2013;44(6):726-9. Crossref

14. Simunovic N, Devereaux PJ, Sprague S, Guyatt $\mathrm{GH}$, Schemitsch E, Debeer J, Bhandari M. Effect of early surgery after hip fracture on mortality and complications: systematic review and meta-analysis. CMAJ 2010;182(15):1609-16. Crossref

15. Shiga $T$, Wajima $Z$, Ohe $Y$. Is operative delay associated with increased mortality of hip fracture patients? Systematic review, meta-analysis, and meta-regression. Can J Anaesth 2008;55(3):146-54. Crossref

16. Association of Anaesthetists of Great Britain and Ireland; Griffiths R, Alper J, Beckingsale A, Goldhill D, Heyburn G, HollowayJ, Leaper E, Parker M, Ridgway S, White S, Wiese M, Wilson I. Management of proximal femoral fractures 2011: Association of Anaesthetists of Great Britain and Ireland. Anaesthesia 2012;67(1):85-98. Crossref 
17. Al-Ani AN, Samuelsson B, TidermarkJ, Norling Å, Ekström W, Cederholm T, Hedström M. Early operation on patients with a hip fracture improved the ability to return to independent living. A prospective study of 850 patients. J Bone Joint Surg Am 2008;90(7):1436-42. Crossref

18. Moran CG, Wenn RT, Sikand M, Taylor AM. Early mortality after hip fracture: is delay before surgery important? J Bone Joint Surg Am 2005;87(3):483-9. Crossref

19. Vidán MT, Sánchez E, Gracia Y, Marañón E, Vaquero J, Serra JA. Causes and effects of surgical delay in patients with hip fracture: a cohort study. Ann Intern Med 2011;155(4):226-33. Crossref

20. Moja L, Piatti A, Pecoraro V, Ricci C, Virgili G, Salanti G, Germagnoli L, Liberati A, Banfi G. Timing matters in hip fracture surgery: patients operated within 48 hours have better outcomes. A meta-analysis and meta-regression of over 190, 000 patients. PLoS One 2012;7(10):e46175. Crossref
21. Khan SK, Kalra S, Khanna A, Thiruvengada MM, Parker MJ. Timing of surgery for hip fractures: a systematic review of 52 published studies involving 291,413 patients. Injury 2009;40(7):692-7. Crossref

22. Smektala R, Endres HG, Dasch B, Maier C, Trampisch HJ, Bonnaire F, Pientka L. The effect of time-to-surgery on outcome in elderly patients with proximal femoral fractures. BMC Musculoskelet Disord 2008;9:171. Crossref

23. Shin WC, Woo SH, Lee SJ, Lee JS, Kim C, Suh KT. Preoperative prevalence of and risk factors for venous thromboembolism in patients with a hip fracture:an indirect multidetector $C T$ venographystudy. J Bone Joint Surg Am 2016;98(24):208995. Crossref 